\title{
Aspectos fenológicos, ecológicos e de produtividade do Pajurá (Couepia bracteosa Bentham) (Chrysobalanaceae) (1)
}

\author{
Martha de Aguiar Falcão ${ }^{(2)}$ \\ Eduardo Lleras ${ }^{3} \mathrm{j}$ \\ Warwick Estevam Kerr $\left({ }^{4}\right)$
}

\begin{abstract}
Resumo
Foi feito um estudo abordando os aspectos fenológicos, ecológicos e de produtividade do Pajurá (Couepia bracteosa Bentham.) para a região de Manaus. A espécie floresce na época mais chuvosa e frutifica no fim do inverno. A safra ocorre no fim do período seco e a mudança foliar antes da floração. Foram encontradas 14 espécies de insetos visitantes pertencentes às ordens Hymenoptera e Lepidoptera. A correlação entre $0 \mathrm{n} .^{\circ}$ de flores e o n. de frutos maduros foi significativa a nivel de $5 \%$, enquanto que com os demais parâmetros de produção foi significativa a nivel de $1 \%$
\end{abstract}

\section{INTRODUÇÃo}

Este é o quarto trabalho da série "Fruteiras da Amazônia", o qual trata dos aspectos feno'ógicos, ecológicos e de produtividade do Pajurá Couepia bracteosa Bentham). Foi realizado com o objetivo de obter dados que possam servir de base para a cultura desta espécie na Amazônia, seja a nível comercial ou de quintal.

\section{MATERIAL E MÉTODOS}

Uma amostra da espécie estudada encontra-se no herbário do INPA resgistrada sob o número 66431, colhida por Falcão, M. A. 192. e idientificada por comparação com outros exemplares seguramente identificados. A metodologia de estudo foi a mesma das espécies anteriormente estudadas (Falcão \& Lleras, 1980 a, b.) exceto quanto ao número de írutos pesados, pois o Pajurá apresenta uma produti- vidade menor em relação às demais espécies, Poraqueiba sericea (Umari), Pourouma cecropiifolia (Mapati) e Couma utilis (Sorva). Por esta razão, em vez de serem pesados 50 frutos de cada árvore foram pesados apenas 25.

As observações no campo foram realizadas semanalmente no período de fevereiro de 1977 a agosto de 1978 .

\section{CONSIDERAÇÕES GERAIS}

Embora o Pajurá (Couepia bracteosa) seja bem representado na Amazônia, pouco se conhece sobre o seu valor economico e nutritivo.

Dentre os trabalhos consultados sobre a espécie, podemos citar o de Pesce (1941) que considerou-a como nativa das matas de terra firme do Estado do Amazonas e comparou o peso de seus frutos com os de uma espécie selvagem (Parınari montana Aubl.). Ducke (194.6) considerou-a como uma espécie nativa, comum nas matas altas de terra firme do Estado do Amazonas e cultivada freqüentemente na cidade de Manaus. Le Cointe (1947) descrevəu-a e fez um ligeiro comentário sobre o mesocarpo dos frutos, achando-o oleaginoso, doce e perfumado. Fonseca (1954) considerou-a como o Pajurá-verdadeiro que amadurece na estação das chuvas. Prance e Silva (1975) e Cavalcante (1976) descreveram pormenorizadamente a planta dando informaçōes sobre a fenológia, distribuição geográfica, procedência e usos da espécie.

(1) - Este trabalho é parte da Tese defendida pelo primeiro autor para obtenção do grau de Mestre em Ciências Biológicas.

(2) - Fundaçäo Universidade do Amazonas, Manaus.

(3) - Instituto Nacional de Pesquisas da Amazônia, M: naus.

(4) - Universidade Federal do Maranhão, São Luís. 
a) ASPECTOS BOTÂNICOS (Fig. 1)

Ncme científico: Couepia bracteosa Bentham. (Chrysobalanaceae).

Nomes vulgares: Brasil: - Pajurá-da-mata e Pajurá-verdadeiro.

Guiana: - Aruadan.

Árvore de 12 a $25 \mathrm{~m}$ de altura, sendo as cultivadas menores; copa ampla e espalhada; folhas simples, alternas, pecioladas; lâmins ovado-elítica a oblonga, coriácea, margem inteira, ápice acuminado, base arrendondada truncada, obtusa ou subcordiforme; estipulas subuladas, caducas; inflorescências em panícuias terminais, racemiformes, e flores herma. froditas, zigomorfas, apopétalas, diclamídeas; receptáculo subséssil, cilindrico; sépalas 5 , livres, imbricadas, brancas, glabras com mar. gens ciliadas; estames $25-26$; anteras dorsifixas, rimosas; carpelo 1 , ovário súpero, unilocular, biovulado, com placentação basal, óvulos anátropos; estilete basal, estigma capitado; bractéolas persistentes; fruto drupa globosa com epicarpo pardo e áspero ao tato devido às inúmeras lenticelas; mesccarpo amarelopardo, bastante espesso, granuloso-carnoso, oleaginoso, doce, saboroso e comestível; endocarpo delgado, lenhoso, frágil, contendo uma grande semente.

b) DISTRIBUIÇÃO GEOGRÁFICA E HABITAT (Fig. 2)

No Estado do Amazonas, ocorre em Manaus, e arredores, e no Rio Negro. No Estado do Pará, é conhecida de Belém, Santarém e do Baixo Amazonas. No Território de Roraima é reportada do Rio Branco. Ocorre também nas Guianas (Pesce 1941; Ducke, 1946; Le Cointe, 1947; Prance e Silva, 1975; Cavalcante, 1976)

Nativa das mates de terra firme e dos capoeirões. (Cavalcante, 1976).

\section{c) Usos}

A árvore é usada para sombreamento de. vido à sua copa frondosa (Prance e Silva, 1975); a madeira é de cor amarelada, dura e pouco resistente (Le Cointe, 1947). Os frutos são comestíveis e podem ser utilizados nə pre- paração de doces. Pouco ou nada se conhece quanto à composição química, e certamente o seu uso merece estudos mais aprofundados

\section{Fenologia}

a) FLORAÇÃO

Durante o presente estudo, a floração da espécie ocorreu entre 22 de abril a 16 de julho (1977) no sítio denominado Rosa de Maio, na Estrada Manaus - Itacoatiara, $\mathrm{Km} 8$, único lugar onde a mesma foi estudada.

O período de floração foi de 86 dias e, embora tenha havido uma variação de alguns dias entre às árvores, tal variação não foi levada em consideração em virtude de as observaçōes serem realizadas semanalmente. A duração média da floração foi de $79,0 \pm 4,24$ dias (Tabela 1).

TABELA 1 - Couepia bracteosa. Duração em dias dos principais eventos durante a frutificaçäo.

DURAÇĀO EM DIAS

\begin{tabular}{|c|c|c|c|c|}
\hline \multirow{2}{*}{ EVENTOS } & \multicolumn{4}{|c|}{ ÁRVORES } \\
\hline & & 1 a & a $10 \mathrm{c}$ & \\
\hline $\begin{array}{l}\text { Início de floração } \\
\text { a } \\
\text { Início de frutificação }\end{array}$ & & $=$ & $45,0 \pm$ & 7,07 \\
\hline $\begin{array}{l}\text { Máxima de floração } \\
\text { a } \\
\text { Início de frutificação }\end{array}$ & $\bar{x}$ & $=$ & $21.5 \pm$ & 9,19 \\
\hline $\begin{array}{l}\text { Final de floraçăo } \\
\text { a } \\
\text { Início de frutificaçăo }\end{array}$ & $\bar{x}$ & $=$ & $28,0 \pm$ & 1,41 \\
\hline Duração de floração & $\bar{x}$ & $=$ & $79,0=$ & 4.24 \\
\hline Duração de frutificação & $\bar{x}$ & $=$ & $276,0=$ & 8,48 \\
\hline $\begin{array}{l}\text { Início de frutificaçăo } \\
\text { a } \\
\text { Início da safra }\end{array}$ & $\bar{x}$ & $=$ & $189,0=$ & 11,31 \\
\hline Duração da safra & $\bar{x}$ & $=$ & $86,5=$ & 3,53 \\
\hline
\end{tabular}


A antese das flores ocorre de preferência, pela parte da manhã entre às 8 e 12 horas, com as flores abrindo gradativamente, sendo que depois de abertas, não fecham mais .

A floração ocorreu no final da época de
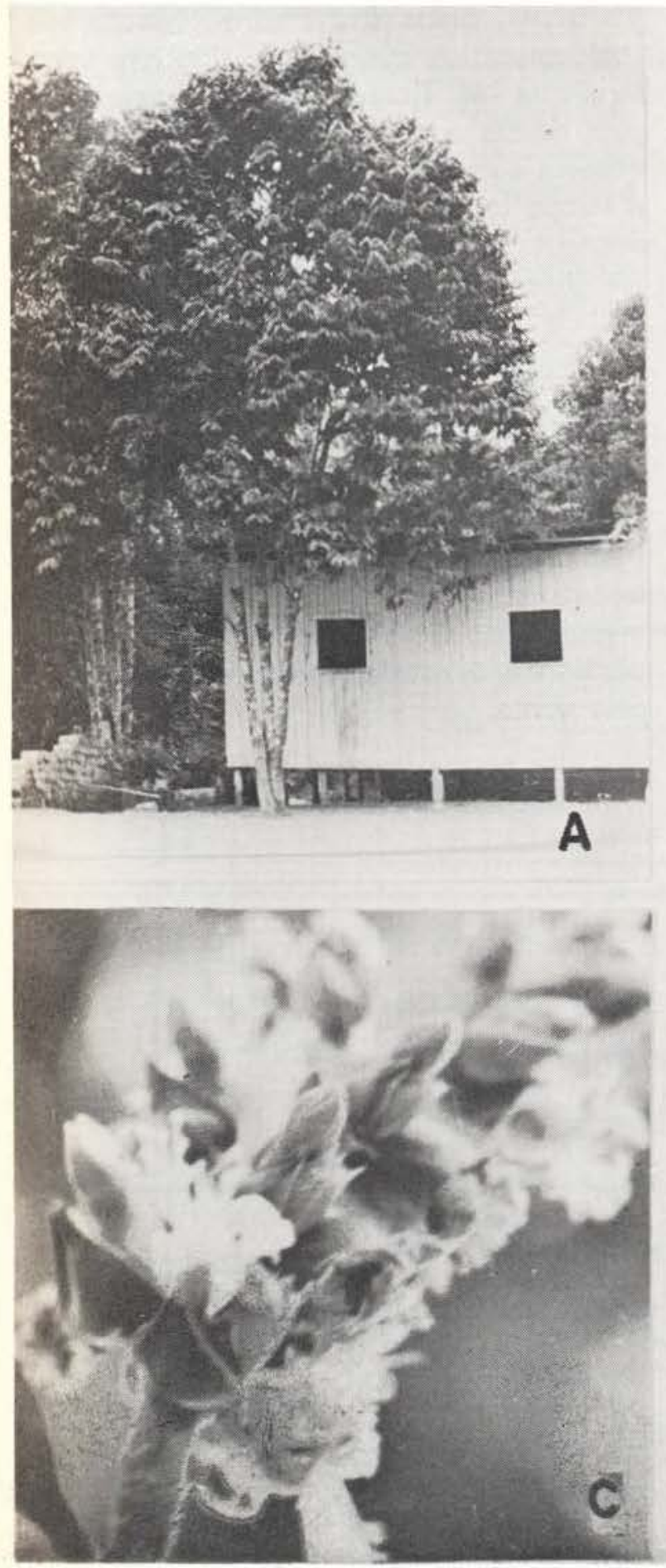

maior precipitação pluviométrica, para a área de Manaus (Tabela 2 - Fig. 3) ligeiramente mais tarde do que o "Mapati" (Pourouma cecropiifolia Mart.), espécie anteriormente estudada (Falcão \& Lleras, 1980 b) .
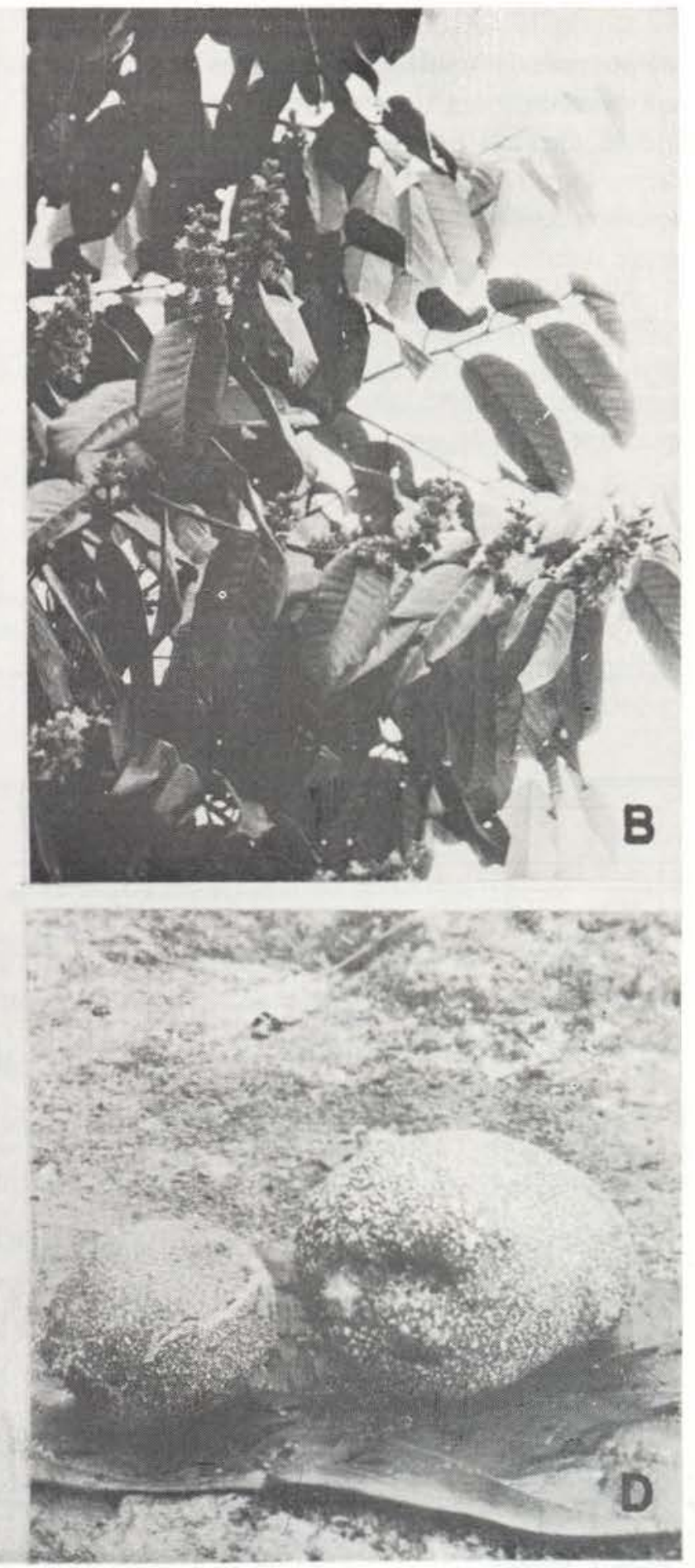

Fig. 1 - Couepia bracteosa: A) Aspecto geral da árvore; B) Galho mostrando inflorescências; C) Detalhe da inflorescência; D) Fruto maduro. 


\section{b) FRUTIFICAÇÃO}

O período de frutificação ocorreu entre o $1^{\text {O }}$ de junho de 1977 e o 27 de março de 1978 com uma duração de 300 dias aproximadamente e com duração da safra de 117 dias.

Como já foi descrito na floração, considerou-se para a frutificação apenas um período nas árvores, com uma duração média de 276,0 $\pm 8,48$ dias. A safra (frutos maduros) das árvores durou em média $86,5 \pm 3,53$ dias com amadurecimento gradativo.

Os frutos quase maduros do "Pajurá" não podem ser retirados das árvores como no caso do "Umarí" (Poraqueiba sericea), sendo que quando isto é feito, em vez de amadurecerem. apodrecem ou ficam com sabor amargo.

\section{c) MUDANÇA FOLIAR}

A queda das folhas variou também nas 10 árvores estudadas. De acordo com as observações obtidas no campo, verificou-se que a mudança foliar ocorreu entre 2 de março e 28 de abril de 1977 com uma duração de 58 dias durante o perícdo chuvoso.

\section{d) INSETOS visitantes}

Foram encontradas 14 espécies de insetos visitantes, todos das ordens Hymenoptera e Lepidoptera. A maior parte dos Hymenoptera freqüenta as flores logo que estas abrem pela manhã enre às 8 e $13 \mathrm{~h}$. A tarde a freqüência é menor. As formigas são constantes o tempo todo e tem comportamento de patruIhamento. Apenas uma espécie de Lepidoptera foi observada visitando as flores pela manhä (Tabela 3) .

Botões florais de 100 inflorescências (10 por árvore) foram revestidos com sacos de filó. De acordo com os cálculos estas 100 inflorescências deveriam produzir aproximadamente 120 frutos, sendo que não foi produzido fruto nenhum. Fazendo-se teste de $X^{2}$ encontrcu-se que a probabilidade de fecundação por insetos é de $99,99 \%$ que demonstra que a espécie não é autofecundada e nem fecundada pelo vento.

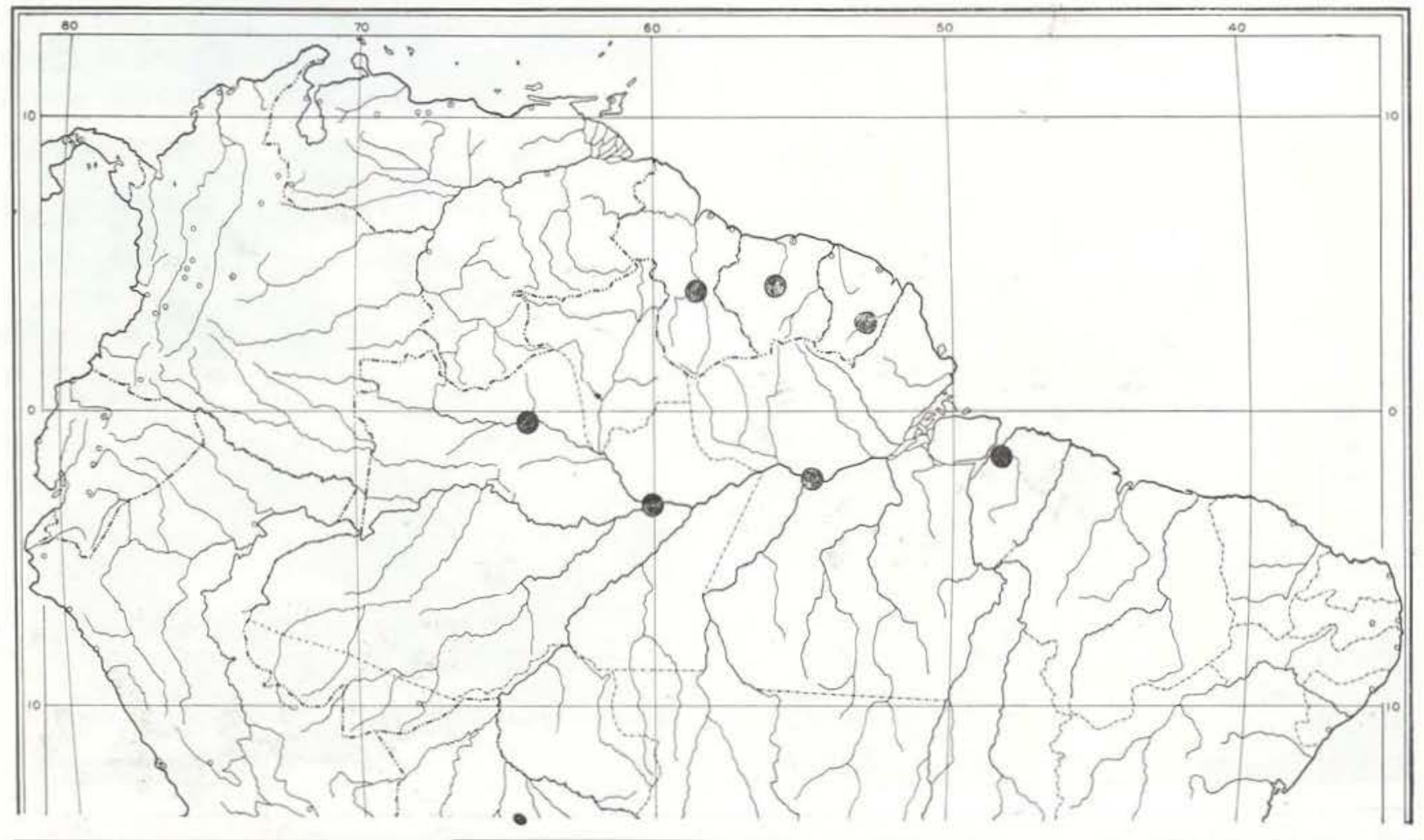

Fig. 2 - Distribuição geográfica conhecida de Couepia bracteosa. 
Além dos visitantes que podem atuar na polinização notou-se, ao remover as cascas e polpas de frutos maduros para pesagem das sementes. que muitos destes tinham sido atacados por larvas de um Coleóptero da familia Curculionidae, larvas estas que brocam as sementes destruindo o embrião.

As operárias de Melipona sp. e Eulaema mocsayi (Friese) que foram observadas visitando as flores de Couepia bracteosa apresentaram grande quantidade de pólem, exclusivamente da espécie, enquanto que Xylocopa frontalis Oliv., Eulaema nigrita (Friese) e Xylocopa sp. transportavam pólen de diversas espécies inclusive do "Pajurá". Nas demais espécies de insetos não foi encontrado pólen (Tabela 3 ) .

Assim, o "Pajurá" (Couepia bracteosa Bentham) como as outras espécies pesquisadas anteriormente (Falcão \& Lleras, 1980 a, b. s/d). não apresenta um poiinizador específico e sim vários polinizadores que compartilham a espécie durante a época de floração.

Os resultados das análises de regressão linear feitas comparando-se diversos parâmetros cie reprodução entre si estăo apresentados nas figuras 4 e 5 .

As correlações entre peso da safra e altura do fuste, diâmetro, altura da cop?, altura total da árvore e idade das árvores não foram significativas (Tabela 5).

Como era de se esperar, em face dos resultados ribtidos nas outras três espécies apre. sentadas anteriormente, a correlação entre o número de flores e frutos imaturos foi altíssi. ma $\left(r=0,960^{* *}\right)$. Também foram muito altas as correlações entre o número de flores e peso da sifra $\left(r=0,895^{* *}\right)$, frutos maduros e ima. turos $\left(r=0,997^{* *}\right)$ e númerc de flores e frutos perdidos $(r=0,968 * *)$.

TABELA 2 - Dados fenológicos de 1977 a 1978 - Couepia bracteosa. As datas indicam o dia em que foi observado, pela primeira vez o evento, sendo as observaçōes semanais.

\begin{tabular}{|c|c|c|c|c|c|c|c|c|c|c|}
\hline \multirow{3}{*}{ ESPECIFICAÇĀO } & \multicolumn{10}{|c|}{ DIAS - MESES } \\
\hline & \multicolumn{7}{|c|}{ ARVORES } & \multicolumn{3}{|c|}{, } \\
\hline & 01 & 02 & 03 & 04 & 05 & 06 & 07 & 08 & 09 & 10 \\
\hline INICIO DA FLORAÇĀO & 22.04 & 01.05 & 22.04 & 22.04 & 01.05 & 22.04 & 01.05 & 01.05 & 22.04 & 22.04 \\
\hline MAIOR FLORAÇĀO & 1505 & 23.05 & 15.05 & 15.05 & 23.05 & 15.05 & 23.05 & 23.05 & 15.05 & 15.05 \\
\hline \multirow[t]{2}{*}{ TÉRMINO DA FLORAÇĀO } & 29.06 & 16.07 & 29.06 & 29.06 & 16.07 & 29.06 & 16.07 & 16.07 & 29.06 & 29.06 \\
\hline & 22.04 & 01.05 & 22.04 & 22.04 & 01.05 & 22.04 & 01.05 & $0 ! .05$ & 22.04 & 22.04 \\
\hline \multirow[t]{2}{*}{ PERIODO DA FLORAÇÃO } & a & a & a & a & a & a & a & a & a & a \\
\hline & 29.06 & 16.07 & 29.06 & 29.06 & 16.07 & 29.06 & 16.07 & 16.07 & 29.03 & 29.05 \\
\hline \multirow[t]{2}{*}{ INICIO DA FRUTIFICAÇÃO } & 01.06 & 19.06 & 01.06 & 01.06 & 19.06 & 01.06 & 19.06 & 19.06 & 01.06 & 01.06 \\
\hline & 28.11 & 02.01 & 28.11 & 28.11 & 02.01 & 28.11 & 02.01 & 02.01 & 28.11 & 28.11 \\
\hline \multirow[t]{3}{*}{ FRUTOS MADUROS (SAFRA) } & a & a & a & a & a & a & a & a & a & a \\
\hline & 25.02 & 27.03 & 25.02 & 25.02 & 27.03 & 2502 & 27.03 & 27.05 & 25.02 & 25.02 \\
\hline & 0106 & 19.06 & 01.06 & 01.06 & 19.06 & 01.06 & 19.06 & 19.06 & 01.06 & 01.06 \\
\hline \multirow[t]{3}{*}{ PERIODO DA FRUTIFICAÇĀO } & a & a & a & a & a & a & a & a & 2 & a \\
\hline & 25.02 & 27.03 & 25.02 & 25.02 & 27.03 & 25.02 & 27.03 & 27.05 & 25.02 & 25.02 \\
\hline & 02.03 & 01.04 & 02.03 & 02.03 & 01.04 & 02.03 & 01.04 & 01.04 & 02.03 & 02.03 \\
\hline \multirow[t]{2}{*}{ MUDANÇA FOLIAR } & a & a & a & a & a & a & a & a & a & a \\
\hline & 30.03 & 28.04 & 30.03 & 30.03 & 28.04 & 30.03 & 28.04 & 28.04 & 30.03 & 30.03 \\
\hline LOCALIZAÇĀO DAS ÁRVORES & & & & ROS & DE & MAIO & & & & \\
\hline
\end{tabular}




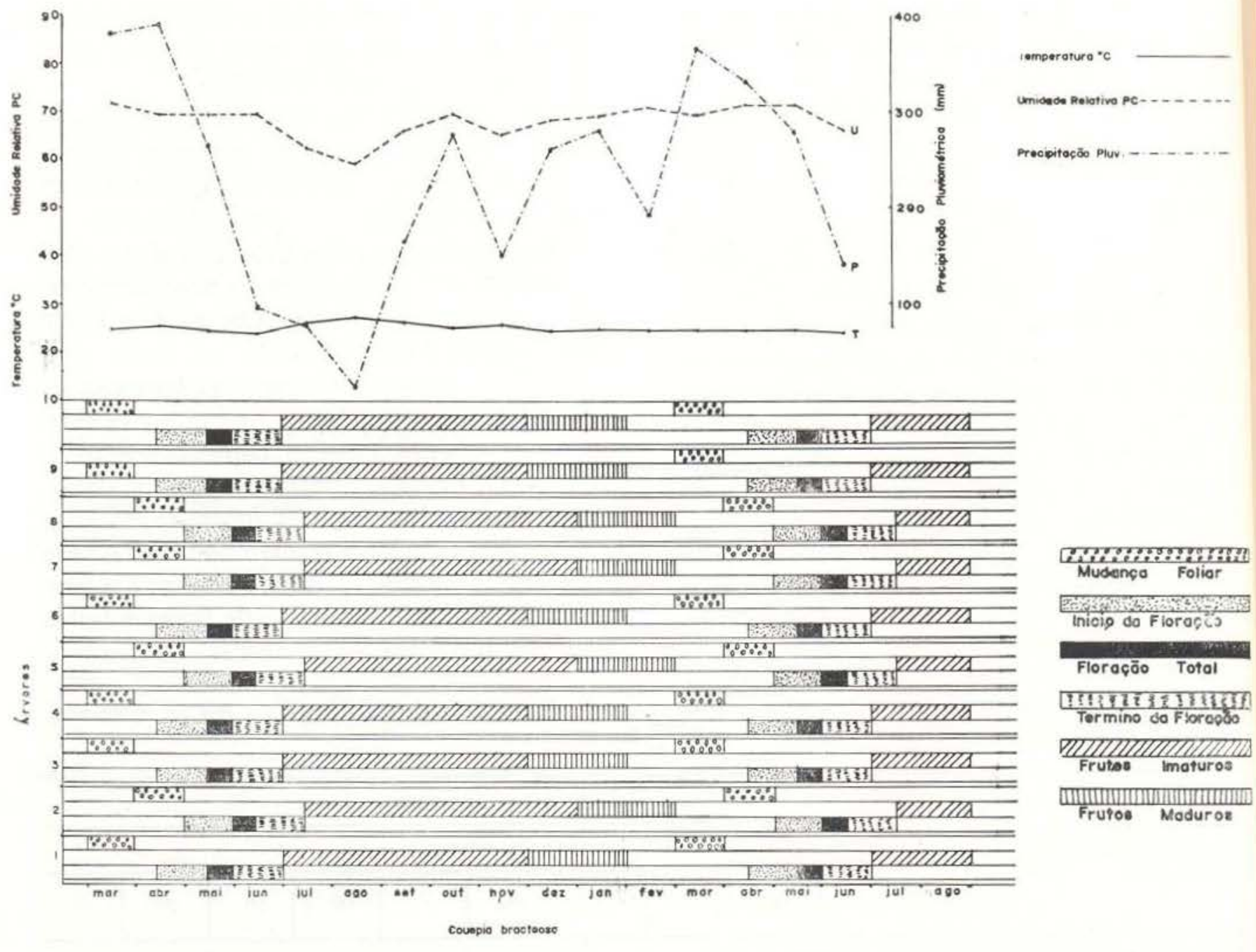

Fig. 3 - Couepia bracteosa. Quadro geral de floraçāo, frutificação, produção e queda de folhas. Na parte superior, dados climatológicos para a área de Manaus (Ribeiro, 1977); na parte inferior, dados fenológicos.

TABELA 3 - Espécies de insetos encontradas nas árvores de Couepia bracteosa e quantidade de gräos de pólen encontrado nas patas dos insetos

\begin{tabular}{|c|c|c|c|c|}
\hline ORDEM & FAMILIA & ESPÉCIE & $\begin{array}{l}\text { GRÃOS DE POLEM } \\
\text { POR AMOSTRA }\end{array}$ & COL. $/ \mathrm{N}^{\circ}$ \\
\hline Hymenoptera & Apidae & Eulaema mocsaryi (Friese) & 748 & Falcão, M., 70 \\
\hline Hymenoptera & Apidae & Eulaema nigrita (Friese) & 620 & Falcäo, M., 50 \\
\hline Hymenoptera & Apidae & Melipona sp. & 840 & Falcão, M., 75 \\
\hline Hymenoptera & Apidae & Melipona sp. & 705 & Falcão, M., 71 \\
\hline Hymenoptera & Apidae & Melipona sp. & 543 & Falcão, M., 74 \\
\hline Hymenoptera & Apidae & Melipona sp. & 516 & Falcão, M., 72 \\
\hline Hymenoptera & Apidae & Xilocopa frontalis Oliv. & 445 & Falcão, M., 76 \\
\hline Hymenoptera & Apidae & Xilocopa sp. & 308 & Falcāo, M., 73 \\
\hline Hymenoptera & Apidae & Não identificado & 589 & Falcão, M., 77 \\
\hline Hymenoptera & Apidae & Năo identificado & 408 & Falcẫo, M., 78 \\
\hline Hymenoptera & Apidae & Não identificado & 870 & Falcão, M., 38 \\
\hline Hymenoptera & Formicidae & Campanotus sp. & 0 & Falcāo, M., 79 \\
\hline Hymenoptera & Hesperidae & Não identificado & 0 & Falcão, M., 80 \\
\hline Hymenoptera & Hesperidae & Não identificado & 0 & Falcão, M., 41 \\
\hline
\end{tabular}


TABELA 4 - Couepia bracteosa, média dos dados básicos de produção incluindo entre outros, flores, frutos imaturos e maduros e peso da safra de arvores localizadas no sítio Rosa de Maio, entre junho de 1977 a março de 1978

\begin{tabular}{|c|c|c|c|c|c|c|c|c|c|c|c|c|c|c|c|c|}
\hline & & & & & & $\mathbf{N}$ & $\hat{U}$ & M & $\mathbf{E}$ & $\mathbf{R}$ & & & & & & \\
\hline \multirow{5}{*}{$\begin{array}{l}\text { 劣 } \\
\text { 总 } \\
\text { 䍐 }\end{array}$} & \multicolumn{3}{|c|}{ GALHOS } & \multicolumn{3}{|c|}{ FLORES } & \multicolumn{7}{|c|}{ FRUTOS } & \multirow{2}{*}{\multicolumn{3}{|c|}{ SEMENTES }} \\
\hline & \multirow{4}{*}{ Árvore } & \multicolumn{2}{|c|}{ Infl. } & \multirow{4}{*}{$\frac{\operatorname{lnfl} .}{\bar{x}}$} & \multirow{4}{*}{ Total } & \multirow{4}{*}{$\begin{array}{c}\% \\
\begin{array}{l}\text { Frutifi- } \\
\text { caram }\end{array}\end{array}$} & \multicolumn{2}{|c|}{ Imaturos } & \multicolumn{5}{|c|}{ Maduros } & & & \\
\hline & & \multirow{3}{*}{$\bar{x}$} & \multirow{3}{*}{ EP } & & & & \multirow{3}{*}{$\begin{array}{l}\text { Por } \\
\text { Galho } \\
\underline{x}\end{array}$} & \multirow{3}{*}{$\begin{array}{c}\text { Árvore } \\
\text { Estim. } \\
\text { na }\end{array}$} & \multirow{3}{*}{ Total } & \multicolumn{3}{|c|}{ Peso } & \multirow{3}{*}{$\begin{array}{l}\text { Estim. } \\
\text { Perd. }\end{array}$} & \multicolumn{3}{|c|}{ Peso } \\
\hline & & & & & & & & & & \multicolumn{2}{|c|}{ Gramas } & Estim. & & \multicolumn{2}{|c|}{ Gramas } & \multirow{2}{*}{$\begin{array}{c}\text { Estim. } \\
\text { KG. }\end{array}$} \\
\hline & & & & & & & & & & $\bar{x}$ & EP & KG. & & $\bar{x}$ & EP & \\
\hline 01 & 33 & 46.33 & 2,97 & 49,14 & 74.594 & 2.24 & 50 & 1.671 & 1.111 & 179,60 & 13.93 & 199,535 & 560 & 41,80 & 3,62 & 46,43 \\
\hline 02 & 18 & 42,33 & 6,16 & 45,73 & 34.843 & 3,15 & 61 & 1.098 & 693 & 148,20 & 8.53 & 102,702 & 405 & 30,00 & 2,12 & 20,79 \\
\hline 03 & 20 & 54,00 & 4,17 & 49.51 & 53.470 & 3,09 & 82 & 1.653 & 1.163 & 233,64 & 14,22 & 271,723 & 490 & 64,48 & 5,42 & 74,99 \\
\hline 04 & 32 & 58,33 & 1,20 & 44,79 & 83.605 & 3,30 & 86 & 2.762 & 1.895 & 203,96 & 14,52 & 386,504 & 867 & 52.96 & 4,32 & 100,35 \\
\hline 05 & 20 & 39,67 & 5,85 & 32,69 & 25.936 & 3,39 & 44 & 880 & 660 & 207,40 & 18,80 & 136,884 & 220 & 65,92 & 4,17 & 43,50 \\
\hline 06 & 23 & 35,00 & 4,73 & 49,70 & 40.008 & 2,59 & 45 & 1.035 & 655 & 213,00 & 16,38 & 139,515 & 380 & 55,48 & 3,85 & 36,33 \\
\hline 07 & 16 & 36,67 & 4,34 & 35,34 & 20.734 & 3,19 & 41 & 661 & 461 & 256,00 & 24,57 & 118,016 & 200 & 81,84 & 8,36 & 37.72 \\
\hline 09 & 15 & 37,00 & 3,79 & 41,03 & 22.771 & 2,70 & 41 & 615 & 440 & 261,32 & 24,61 & 114,980 & 175 & 74,04 & 6,24 & 32,57 \\
\hline 08 & 08 & 36,33 & 5,85 & 39,54 & 11.491 & 2,41 & 34 & 277 & 202 & 170,52 & 9,66 & 34,445 & 75 & 45,00 & 3,04 & 9,09 \\
\hline 10 & 07 & 30.00 & 2,65 & 40,86 & 3.580 & 2,74 & 33 & 235 & 205 & 229.00 & 29.03 & 45,945 & 30 & 78.00 & 8.57 & 15,99 \\
\hline
\end{tabular}


TABELA 5 - Medidas de diâmetro, altura do fuste, altura total e idade das árvores estudadas de Couepia bracteosa

\begin{tabular}{|c|c|c|c|c|c|}
\hline Local & Arvores & $\begin{array}{l}\text { Diâmetro } \\
(\mathrm{cm})\end{array}$ & $\begin{array}{l}\text { Altura do fuste } \\
(\mathrm{m})\end{array}$ & $\begin{array}{l}\text { Altura total } \\
(\mathrm{m})\end{array}$ & $\begin{array}{l}\text { Idade } \\
\text { (anos) }\end{array}$ \\
\hline \multirow{6}{*}{ Sitio } & 1 & 14,65 & 3,00 & 6,00 & 12 aprox. \\
\hline & 2 & 12,74 & 2,50 & 5,50 & 12 aprox. \\
\hline & 3 & 20,70 & 3,50 & 7,50 & 12 aprox. \\
\hline & 4 & 30,57 & 4,50 & 10,50 & 60 aprox. \\
\hline & 5 & 29,62 & 5,00 & 17,00 & 60 aprox. \\
\hline & 6 & 29,62 & 9,00 & 23,00 & 60 aprox. \\
\hline \multirow[t]{4}{*}{ Rosa de Maio } & 7 & 20,70 & 4,00 & 12,00 & 60 aprox. \\
\hline & 8 & 21,02 & 9,00 & 22,00 & 60 aprox. \\
\hline & 9 & 21,97 & 3,50 & 10,50 & 60 aprox. \\
\hline & 10 & 25,48 & 4,50 & 11,50 & 60 aprox. \\
\hline
\end{tabular}
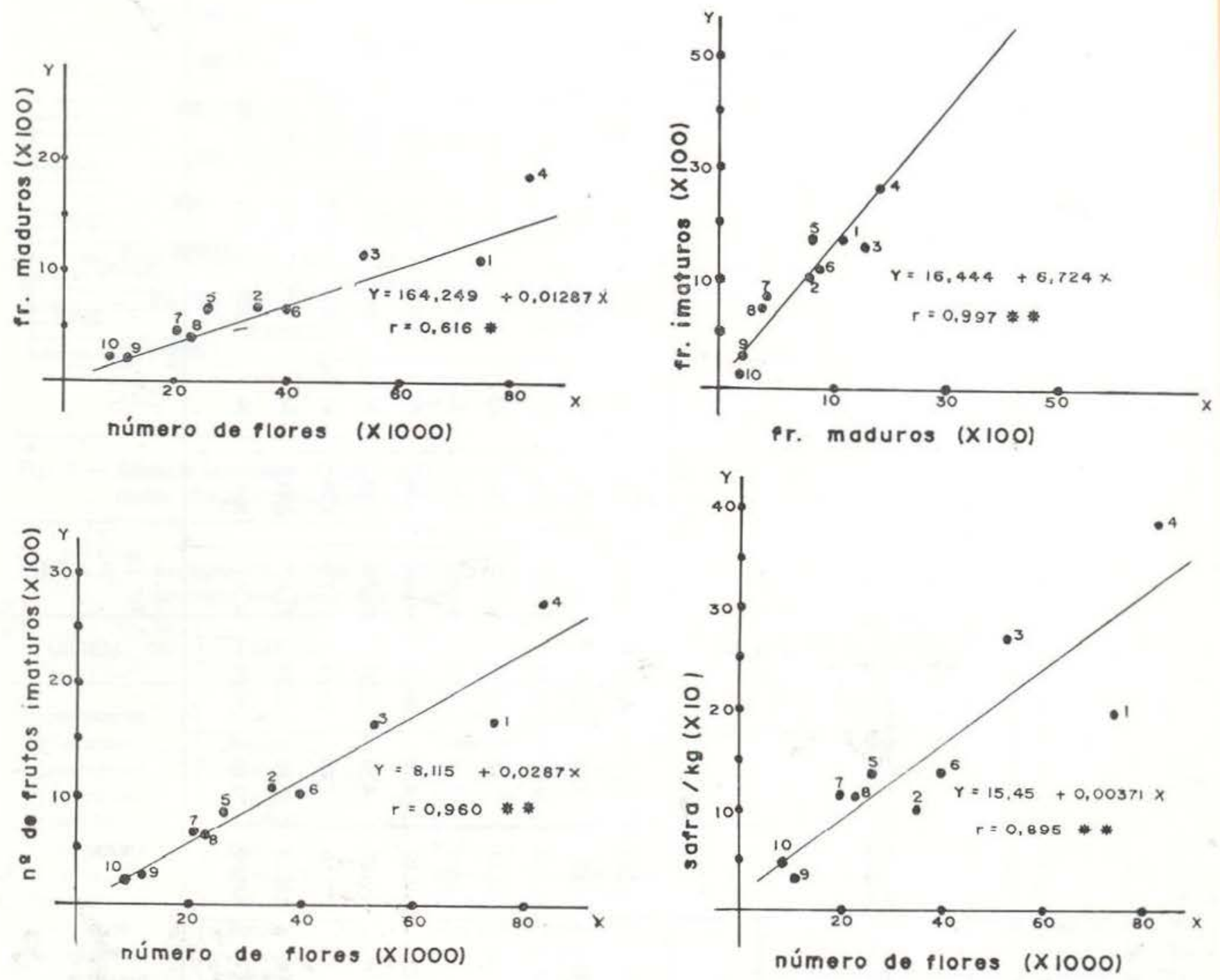

Fig. 4 - Couepia bracteosa. Análise de regressão linear comparando-se número de flores $(\bar{X})$ com outros dados de produção $(\mathrm{Y})$ sítio Rosa de Maio. $r=$ coeficiente de correlação entre $\mathrm{X}$ e $\mathrm{Y}$. Os números correspondem aos número das árvores. 
Menos alta foi a correlação entre número de flores e números de frutos maduros $(r=$ $\left.0,516^{*}\right)$ porém não deixando de ser estatisticamente significativa.

Analisando se os dados referentes aos pesos do fruto e comparando-se com os da polpa e semente (Fig. 6), nota-se que há uma correlação muito alta entre peso total do fruto e da poipa $\left(=r 0,982^{* *}\right)$. Sendo que, há uma só semente por fruto, era de esperar-se que existisse uma correlação também alta entre peso tota! dos frutos e peso das sementes, o que foi confirmado $\left(r=0,818^{* \prime \prime}\right)$.

Como no caso da "sorva" [Couma utilis (Mart) M. Arg.], fruto e peso da polpa apresentam uma bimodalidade evidente. A variancia das sementes é menor que a do peso total e peso da polpa. No "Pajurá", porém, as sementes são tão variáveis quanto os frutos (Fig. 6) .

Em termos gerais, os resultados aqui apresentados coincidem com os das outras espécies estudadas (Falcão \& Lleras, 1980 a, b e s.d.). Assim, mais uma vez os resultados sugerem que a perda de frutos não é fortuita, o seu número de flores é uma expressão de que 0 peso da safra parece ser controlado endogenamente.

A polinização no "Pajurá" é certamente bastante baixa $(2,96 \%)$, sendo a mais baixa das quatro espécies até agora estudadas (Ibid.); a espécie comparte uma série, de polinizado.

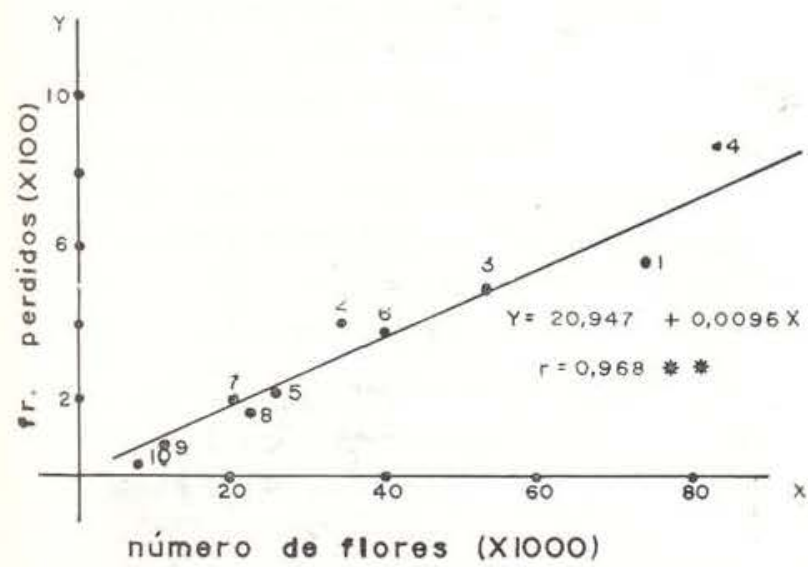

Fig. 5 - Couepia bracteosa. Regressão entre o número de flores $(X)$ e número de frutos perdidos $(\mathrm{Y})$

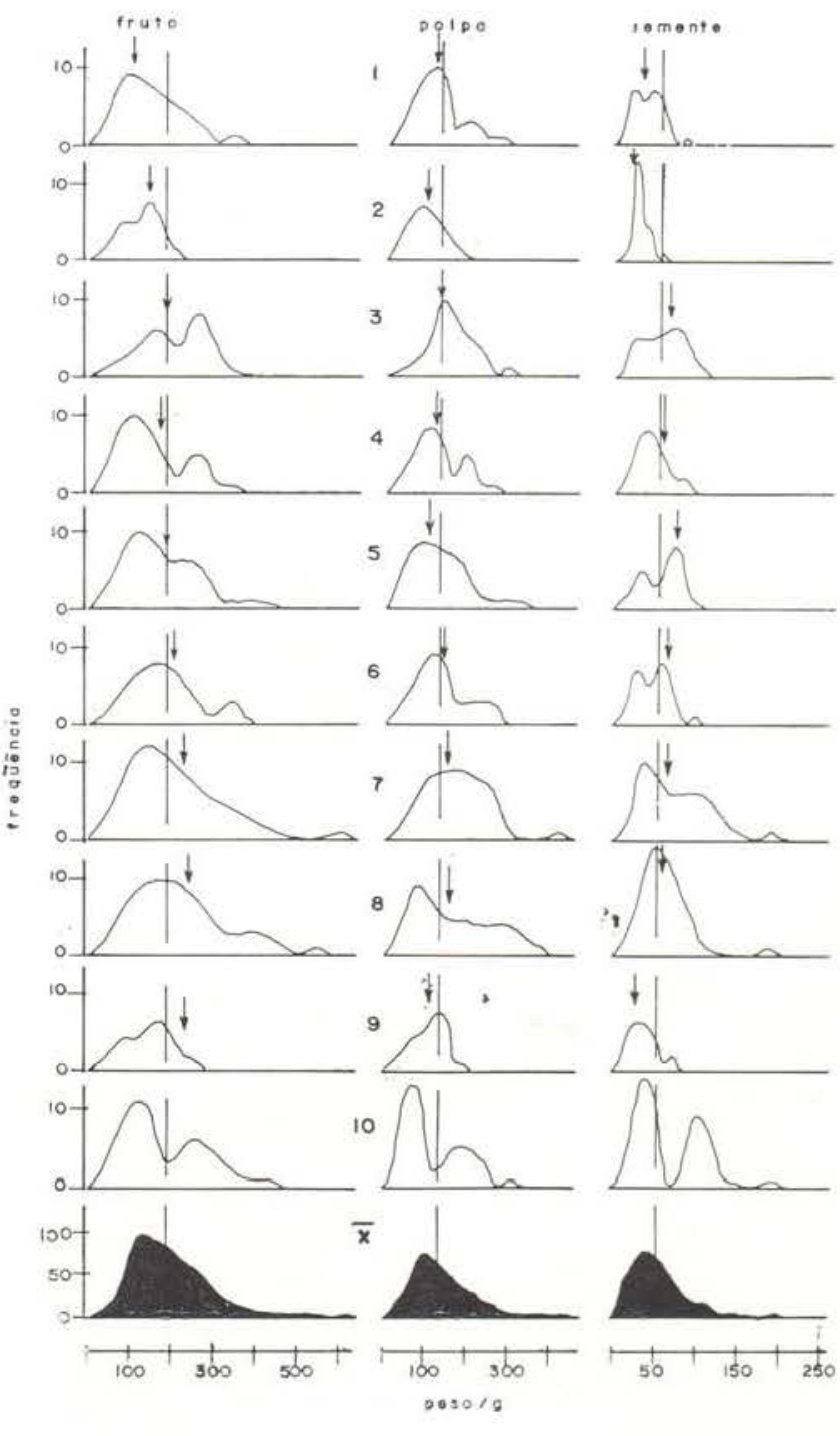

Fig. 6-Couepia bracteosa. Freqüências de pesos de fruto total e sementes das árvores, e das médias das mesmas. A linha que atravessa os gráficos representa a média das médias; a seta em cada gráfico representa a média do mesmo. (1977/1978).

res com a "sorva" (de fato na átea de estudo as duas espécies encontram-se misturadas) destacando-se Eulaema mocsaryi, Eulaema nigrita e Xylocopa frontalis.

Há a possibilidade de existir uma concorrência de polinização entre as duas espécies; porém, com base nos dados coletados, não é possivel afirmar isto categoricamente.

Como nos casos anteriores, são necessárias mais pesquisas nesta espécie, pois ainda que tenham sido elucidados alguns fatos a seu 
respeito, tem sido também levantadas mais dúvides e mais exigências de pesquisas além das existentes antes de iniciar este trabalho.

\section{Agradecimentos}

Agradecemos pelas sugestões críticas, revisão e apoio à Maria Lúcia Absy, Herbert Otto Rogert Shubart, Ângela Maria Conte Leite, Lea Maria Medeiros Carreira, Hugo Menezes dos Santos e sua equipe do Processamento de Dados, A.lgenir Suano da Silva e João Chrisostomo de Oliveira, assim como a todas as pessoas que colaboraram direta ou indiretamente. No trabaiho de campo somos gratos a Osmarino Santos Monteiro pela sua eficiente colaboração.

\section{SUMMARY}

This paper presents data on phenology, ecology and productivity of Pajurá (Couepia bracteosa Bentham) for the vicinity of Manaus. The species flowers at the height of the rainy season with fruit set at the end of the same. The crop is at the end of the dry season with leaf set just before flowering. Fourteen species of insects were found visiting the flowers, of which thirteen were Hymenoptera and one Lepidoptera. The correlation between number of flowers and number of mature fruit was significant at the $5 \%$ level, being significant at the $1 \%$ level with other parameters such as fruit lost. number ot immature fruit and crop weight, suggesting once again endogenous control of flowering and fruiting

\section{REFERENCIAS BIBLIOGRÁFICAS}

CAVALCANTE, P.B.

1976 - Frutas Comestiveis da Amazônia. 3 ed. Be. lém. INPA. $166 \mathrm{p}$.

DUCKE, A.

1946 - Plantas de Cultura pré-colombiana na Amazônia brasileira Bol. Téc. Inst. Agron. Norte. Belém (8): 1-24.

FALCĀO, M.A. \& LLERAS, E.

1980a- Aspectos Fenológicos, Ecológicos e de Produtividade do Umari (Poraqueiba sericea) Tulasne. Acta Amazônica, 10 (3): 445-462.

1980b- Aspectos Fenológicos, Ecológicos e de Produtividade do Mapati (Pourouma cecropiifolia). Acta Amazonica, 10 (4): 711-724.

s/d - Aspectos Fenológicos, Ecológicos e de Produtividade da Sorva (Couma utilis). No prelo.

FONSECA, E.T.

1954 - Frutas do Brasil. Rio de Janeiro, Inst. Nac. Livro. 281p.

LE COINTE, P.

1947 - Amazônia brasileira II. Arvores e Plantas Úteis (Indígenas e Aclimatadas) 2 ed. São Paulo, Ed. Nacional. 506p.

PESCE, C,

1941 - Oleaginosas da Amazônia. Belém, R. Veterinária, (2): 1-128.

PRANCE, G.T. \& SILVA, M.F. da

1975 - Árvores de Manaus, Manaus, INPA. 312p.

RIBEIRO, M.N.G.

1977 - Boletim Meteorológico. Instituto Nacional de Pesquisas da Amazônia, setor de Meteorologia, Manaus. 14p.

(Aceito para publicação em 22/04/81) 